\title{
ADVANCING RECIPROCITY IN CROSS-CULTURAL LEADERSHIP COACHING
}

\begin{abstract}
Leadership coaching is a method of learning and development. This brief describes a leadership practice that was effective in navigating culture when it became a relevant factor in maintaining a reciprocal leadership learning and development partnership. Using a community-based inquiry method, we utilized and examined leadership coaching practice as it attempted to support cross-cultural leadership learning and development that was running alongside an international development project in Kenya. Readers will gain a better understanding of a cross-cultural leadership coaching practice.
\end{abstract}

\section{Introduction}

Issue Statement. Leadership learning and development is increasing taking on a global dimension. Leadership coaching is a popular development tool. Leadership Coaching, as a learning and development practice, needs to accommodate inter- and cross-cultural contexts. A commitment to reciprocity is one conceptual framework that is potentially helpful in navigating culture when it becomes a relevant feature in leadership coaching partnerships. Reciprocal leadership coaching partnership become increasingly important in crosscultural contexts. At a very basic level, reciprocal leadership coaching partnerships use dialogue to create openings that are able to accept and recognize a range of ways of knowing and being in cultural systems. The purpose of this practice paper is to unpack what is required to support reciprocal crosscultural leadership coaching partnerships.
Forming a Coaching Relationship. We, Brandon and Beth, met as part of the 2016 Young African Leaders Initiative (YALI), a U.S. Department of State program invest in the next generation of African leaders. Beth was selected for the Mandela Washington Fellowship-representing Kenya. Brandon was the Co-Academic Director of the YALI Civic Leadership Institute hosted by the Staley School of Leadership Studies at Kansas State University which provided academic coursework, leadership training, and networking for a cohort of Fellows Participation in the 6-week institute gave us a common experience and opportunity to develop a strong leadership coaching partnership, interrogate common civic leadership practices across culture and context, and for Brandon, to deepen his understanding of human rights regimes related to disability in Kenya. Our affiliation with YALI qualified us to apply for a U.S. Department of State/IREX Reciprocal Exchange Program Grant in 2017. The grant program was intended to support continued learning 
collaborations and deepen understanding between U.S. citizens and Mandela Washington Fellows.

At the time of the project, Beth was launching an effort to (a) increase the capacity of caregivers in Murang'a County, Kenya to advocate on behalf of children experiencing disabilities, and (b) develop public capacity to advocate the Kenyan government to recognize the rights of people with developmental disabilities. Advancing a community development effort to support the rights of people with disabilities can be understood as leadership within a Complex Adaptive System (Holland, 2006). The objective of our Reciprocal Exchange Program project was to conduct initial community organizing work with caregivers in the area and provide a two day advocacy and civic leadership training. Beth was responsible for the training and the curriculum that was delivered to participants in the local language of Kikuyu. She had a familial connection to the region and worked to design a leadership curriculum that honored affective relationships between leaders and followers, recognized common geographical and tribal affiliations, and focused on a shared educational context (Wolgramm, Spiller, \& Voyageur, 2016).

The curriculum design and delivery was the experiential context in which our leadership coaching partnership and practice was contextualized. Brandon's role in the project was to support the leadership education experience by providing Beth leadership coaching. In addition to designing a leadership education experience, the leadership coaching component was intended to position Beth's leadership learning and development within a larger experiential learning and change effort. As Beth diagnosed the leadership challenge in front of her, she began working with Brandon in a series of leadership coaching sessions designed to make sense of the ways her leadership work was situated within larger social, political, economic, and cultural systems.
Purpose. The purpose of this application brief is to outline a process of inquiry we engaged in as part of our coaching relationship. We sought to more fully understand the leadership coaching processes and practices necessary to maintain reciprocity, which is essential in supporting meaningful crosscultural leadership learning and development. The primary question guiding our critical practice inquiry was: How are levels of reciprocity maintained in cross-cultural leadership coaching practice? For the purpose of this inquiry, we define crosscultural leadership coaching as instances when culture becomes a relevant factor in the leadership coaching process. Using a community-based inquiry approach, we will describe our journey of identifying and unpacking coaching instances in which "culture surfaces as a significant variable" (Abbot \& Salomaa, 2017, p. 465). Unpacking lessons learned through our own cross-cultural leadership coaching experience will help other leadership educators, trainers, and developers to better account culture when it becomes a relevant factor in establishing and maintaining reciprocal leadership learning and development partnerships.

\section{Review of Related Literature}

One of the unique features of our leadership coaching relationship was that we were working across culture and context. We spent a significant amount of time and attention negotiating a leadership coaching relationship that not only accounted for difference across culture and context, but also was organized in ways that honored degrees of reciprocity between the two of us. In addition to our shared commitment to maintain standards set by the International Coach Federation, we also recognized an additional obligation to account for the nuances of culture and context. In our coaching relationship, we explored four areas of the literature as they related to our specific leadership coaching partnership and practice: (a) 
reciprocal learning partnerships, (b) discourses of social change, (c) experiential learning, and (d). adapting to cultural difference in systems.

Establishing Reciprocity. We operationalized our cross-cultural leadership coaching partnership within a framework of reciprocity. Dositilio et al. (2012) suggest that reciprocity has three distinct, but related orientations: (a) exchange - an orientation to reciprocity that is an "interchange of benefits, resources, and actions" (p. 19); (b) influence - an orientation to reciprocity that is "expressed as a relational connection that is informed by personal, social, and environmental contexts" (p. 20); and (c) generativity - an orientation to reciprocity that may involve "transformation of individual ways of knowing and being of the systems of which the relationship is part. The collaboration may extend beyond the initial focus of outcomes, as ways of knowing, and as systems of belonging evolve" (p. 20). As coach and coachee, we worked to advance a cross-cultural coaching relationship aligning with a generative orientation to reciprocity.

Cross-cultural coaching relationships that include a commitment to reciprocity link the learning and development experience to relational theories of leadership. Uhl-Bien (2006) defines relational leadership as "a social influence process through which emergent coordination (i.e., evolving social order) and change (e.g., new values, attitudes, approaches, behaviors, and ideologies) are constructed and produced" (p. 655). This perspective complicates the focus placed on leader-follower dyads; instead leadership and leadership activity is produced by relationships and through different ways of knowing, being, and existing within systems. Cross-cultural leadership coaching partnerships ought to attend to the contexts in which relationships co-emerge.

Leadership coaching across culture and context requires coaches and coachees to closely interrogate the frameworks they use to make sense of the coachcoachee partnership processes. Rosinski (2003) suggests that "traditional coaching has implicitly reflected particular norms, values, and basic assumptions that reflect those originating of the culture of the field of coaching in the United States, and do not necessarily hold true universally" (pp. 2021). In our coaching relationship, we intentionally considered ways to elevate the perspectives and voice of participants from the rural Kenyan community in which the leadership development was situated, while working to decenter leadership concepts from the Global North (in this case, the United States). We intentionally attempted to avoid leadership and progress narratives that center western norms and maintain mechanisms of neo-colonialism (See Allen, 2016 for a description of what would be required to decolonize leadership progress and development discourses). We approached our leadership coaching practice through a community-engaged scholarship framework (e.g., Dodge, Ospina, \& Foldy, 2005; Heron \& Reason, 2001; Stoecker, 2012). Learning produced from the coaching sessions was intentionally organized in ways that could be integrated into future coaching efforts as a way to increase our capacity for critical practice.

Role of Discourse as Strategic Social Change. Discursive leadership theory offers a critical lens to understand and interrogate the relationship between leadership activity and language. According to Fairhurst (2007), discursive approaches to leadership "focus on language in use, interaction process, and/or discursive formations" (p. 9). Viewing our leadership coaching partnership processes through a discursive lens was an intentional choice - an attempt to shift from individual understanding to acknowledging collective social and cultural systems (Ospina \& Foldy, 2016). This critical frame created a holding space for meta-discussion of how relevant leadership concepts from the Global North leadership literature does not account for cultural and contextual difference of rural Kenya. The coaching process created a space to problematize associated concepts and rearticulate ideas about leadership that illustrated potential pathways that could center the voices, perspectives, and ways of knowing practiced by community members in Murang'a. According to Ospina \& Foldy 
(2016),

attention to discourse at the microlevel conversation and speech acts, and to discourse embedded in broader macrolevel assumptions, guides us in recognizing leadership, viewed as an emergent process of influence characterized by the management of meaning through the use of talk and corresponding actions to advance a task or goal. (p. 4)

The critical approach to discourse was an important component of our practice and acknowledged how leadership learning and development was contextually embedded in community.

Experiential Learning. Kolb (1984) is the starting point for many practitioners interested in experiential learning. Our practice relied upon a critical approach to experiential learning. Carroll (2015) describes the experiential leadership tradition as being "interested in the everydayness of experience and how we connect to the multitude of things that we are involved in over the course of our days, weeks, and lives" (p. 94). We used a critical experiential lens to make sense of the micro-discourse present in our leadership coaching conversations.

Experiential learning approaches are intended to surface learning and knowledge about leadership through what Cunliffe (2009) refers to as "dialoguewith-self" (p. 98). Dialogue-with-self is a practice in which a group of individuals interested in exercising leadership have the capacity to ask themselves questions about the responses of others and interpretations of shared experiences. Deepening the capacity to think about our own role in a system opens the possibility to enact leadership. Raelin (2007) refers to this as being a reflective community. Critical reflexivity allows for leadership to be constructed as a social, political, economic, and ecological phenomenon both at individual and collective levels. The act of being in dialoguewith-self not only deepens understanding at the individual level but expands the capacity of entire communities to make sense of leadership activity.

Adapting to Cultural Difference in Systems.

While there are multiple approaches to systems thinking, in our project we focused on Senge's (2006) The Fifth Discipline and the associated concept of feedback loops. Capturing feedback loops is an essential element in realizing learning organizations and diagnosing the operations of systems. The core dimensions of a learning organization are the following: (a) spiritual dimensions - to see and speak to diverse people; (b) emotional dimensions manage self in service of higher purpose; (c) physical dimensions - bring people together and creating the conditions to collaborate; and (d) mental dimensions - to see and navigate how collective language and thinking impact outcomes. Stroh (2015) extends an understanding of feedback loops generally to systems thinking as the "ability to understand these interconnections in such a way as to achieve a desired purpose" (p. 16).

Additionally, we worked from Bennett's (1993) model of intercultural sensitivity, which illustrates the ways individuals respond to, and build capacity for working effectively across, cultural difference. Rosinski (2003) extended Bennett's model of intercultural sensitivity to leadership coaching. Passmore \& Law (2013) completed a survey of existing models for cross-cultural coaching, producing what they referred to as the "Pragmatic Implementation Model (PIM)" (p. 4). The PIM suggests that to practice leadership coaching across culture and context requires continuous professional development, appreciation of the cultural environment, coach fluidity and capacity for integration, cross-cultural emotional intelligence, and communication methods and feedback (Passmore \& Law, 2013). Brandon has completed the Intercultural Development Inventory (IDI) assessment and uses the framework in some of his leadership courses (Hammer, 2011). The IDI provided a specific frame and shared language to talk about relevant factors in our leadership coaching conversations. The IDI framework was most helpful in directly speaking to underlying 
cultural assumptions embedded in coaching questions and responses.

\section{Description of Application}

Early on in the leadership coaching relationship, moments when culture became a relevant factor in the coaching conversation would lead us to stop coaching and resolve the relevant dimension outside of the leadership coaching process. Our leadership coaching relationship become more capable of adjusting to relevant cultural variables within the leadership coaching process over time.

Next, we will share several examples from our leadership coaching experience, specifically reflecting on instances in which culture became a relevant factor. Designing and executing a crosscultural leadership coaching relationship that supported Beth's efforts to exercise the types of leadership necessary to make change in her community required us both to account for the intersection of identity, power, and systems. In this section, we overlay a critical lens in order to illustrate how our leadership coaching practice attended to questions of identity, power, and shared experience in systems as part of our sense-making process.

Identity. One way in which we developed an understanding of each other's understanding of self was by writing and sharing subjectivity statements. Our partnership began by developing subjectivity statements. The subjectivity statement gave us a specific text to examine when making sense of instances in which culture became a relevant factor in negotiating cultural context and maintaining a reciprocal leadership coaching partnership. Below you will find each of our subjectivity statements used in our leadership coaching practice. You will notice that this section of the manuscript shifts to first-person tense. We made this choice intentionally to more accurately reflect how the subjectivity statements were introduced into the coaching partnership.
Beth's subjectivity statement. I experience cerebral palsy. Born into a middle-income family that lived in Nairobi, I had more opportunities than most Kenyans who experience cerebral palsy. I believe that communities play a key role in determining the quality of life of individuals experiencing disabilities and works closely with local community members in rural and slum regions in Kenya to develop public speaking and advocacy skills, increase confidence, and strengthen partnerships. Murang'a County is an hour's drive from Nairobi and my ancestral home. Almost all of its inhabitants belong to the Kikuyu ethnic group which is markedly patriarchal and ableist. Among the Kikuyus, a disabled woman falls in the lowest strata of human beings and during my regular visits to Murang'a in preparation for the project, I encountered rejection and opposition from the community. However, I received a lot of support from those who had been invited to participate in the training. Caregivers were especially intrigued that a white man would visit their homes. Like many Kenyans, residents of Murang'a County quickly notice white people as different and treat them as such.

Brandon's subjectivity statement. I am a white, able-bodied, man from the United States. The combination of my social identities and location gives me a large degree of choice and movement. Not only am I able to navigate physical spaces with relative ease, as a U.S. citizen, I have the ability to access global travel in a way that the majority of the world's population does not. The social, political, and economic systems of the Global North have given me a distinct advantage to make sense of development regimes, civic leadership activity, human rights traditions, and the informal practices of the Western world. 
Attending to identity was an important element of our cross-cultural leadership coaching practice. Understanding how we each made sense of self and how our identity shaped the ways we experienced our social location within larger systems was essential to maintaining a reciprocal coaching relationship capable of navigating culture. Each of our experiences was embedded in culture and context; understanding how we made sense of self allowed each of us to hold space in the coaching partnership when culture become a relevant factor. Talking, remaining curious, and intentionally trying to understand how we each made sense of identity created a conceptual framework that opened cross-cultural possibility. Intentionally developing our subjectivity statements and referring to them through the coaching partnership was a helpful leadership coaching practice.

Power. We were very intentional in how we developed the leadership coaching relationship. Specifically, we took precautions to avoid designing a leadership practice and coaching relationship that "extracted" knowledge from an indigenous community for the direct gain of leadership educators and coaches who were not from the community in which the work was being done. Second, we negotiated and agreed to the terms of a coaching relationship and the general direction of this practice-oriented inquiry. We agreed it would be best to record our coaching sessions and draw upon the recordings as a text that could support debrief and reflection in order to deepen our understanding of cross-cultural leadership coaching practice. The audio recordings and associated reflective writing served as a record for this practice inquiry. Keeping detailed notes, records, and transcripts of associated leadership conversations was very helpful practice to support our learning. In our leadership coaching sessions and written reflections, we attempted to access what Fairhurst and Antonakis (2012) refers to as: "dialogical practices [that] open up to relationality, open up possibilities, and open up space for self and others to co-emerge and to 'go on' in difference but equal (not right/ wrong or better/wrong relations) relations" (p. 469). Our interactions and leadership coaching became the focus of our learning and development.

An important learning outcome and theme that resulted from this practice inquiry was how we worked to maintain a reciprocal coaching relationship by explicitly accounting for our leadership educator identities and social location (GuramatunhuCooper \& Lyons, 2017). Intentionally accounting for power helped us navigate moments in the coaching process when culture became a relevant factor for learning and development. For example, Beth invited Brandon to interrogate and question the assumptions he brought to his leadership educator and coaching identities as a result of his whiteness, physical ability, citizenship, and class position. Beth helped Brandon reflect on his positionality before travelling to Kenya. We did this work through an exchange of written reflections and digital photographs that we shared through a collaborative Google document. This intentional commitment to reciprocal learning helped Brandon to position his experience as a leadership coach and educator within a larger global context. This lens allowed Brandon to interrogate assumptions that he, consciously and unconsciously, relied upon when thinking about leadership learning and development in the context of leadership coaching. For Beth, having formal support from the U.S. Department of State/IREX and collaborating with an academic from an institution of higher education in the US attached symbolic significance to her organization and work in Kenya. At the same time that others within and outside our immediate system ascribed power to her work, she was also prepared for and expected to face open discrimination as a leadership educator with Cerebral Palsy. Beth often used the leadership coaching sessions to make sense of tensions associated with being honored in one context and then worrying that her views were not being recognized by others as a result of her disability.

Shared Experience in Systems. We completed an Institutional Review Board (IRB) application and had all the participants sign or verbally acknowledge 
consent to participate in a training that would create the experience-based system that informed our leadership coaching sessions. This IRB was an effort to formally articulate the assumptions of our critical leadership coaching practice as an overarching experience. The process of responding to various ethical considerations and documenting our shared responses in writing helped establish an initial partnership and demonstrate a recommended practice of highlighting and making sense of a shared experience. Completing the IRB, established a norm in our leadership coaching practice in which shared experience became a vehicle to examine how and when culture became a relevant concern for maintaining a reciprocal leadership coaching partnership.

We used common experiences as a way to construct a cross-cultural leadership coaching framework. We would revisit significant moments in our shared experience to help us better understand how we each navigated systems. The shared experience helped to contextualize how each of us made sense of difficult social, cultural, political, and economic systems. The first specific example was when we debriefed a common Kansas Leadership Center (KLC) training we both experienced. The Kansas context and predominately white, rural audience highlighted ways in which we relied on different cultural frameworks to make sense of associated concepts presented in the training and leadership activity generally. The KLC experience provided a shared leadership practice in which we could unpack the ethical and cultural implications of moving leadership concepts from a western context to a rural community in Kenya. The second example was the analysis of a reflective story Beth wrote that described a shared experience of when a police officer unjustly pulled us over in Nairobi and attempted to coerce us into giving him a bribe. We felt that the distinct experience with the Kenyan police officer illustrated important principles about how we both made sense of a shared experience in which culture became a significant variable in the everyday practice that informed our leadership coaching partnership. The shared experience of navigating police authority in Nairobi created an opportunity to consider the assumptions we each brought to the leadership coaching partnership related to authority, agency, and the capacity to push up against unjust systems. The two experiences were not only significant to our shared leadership coaching practice but helped foster a coemergence of a common framework to talk about how cultural and context was a relevant factor in maintaining our leadership coaching partnership.

\section{Discussion and Recommendations}

The evolving nature of our leadership coaching partnership was the result of a shared conceptual reference point we co-emerged together to make sense of our coaching exchanges. These reference points became a way to slow down the exchange and adjust the way we negotiated the coaching agreement within the leadership coaching process. Over time, these adjustments begun to feel more natural and streamlined within the coaching conversation. The capacity to create these conditions in our coaching conversations was the result of intentional efforts to connect questions of power, identity, and social location within systems to experiences that were shared in common. The effort to connect to shared experience allowed us to share how a specific experience was relevant from dimensions of identity, power, and systems. Our inquiry reveals that reciprocal cross-cultural leadership coaching relationships can account for culture as a relevant factor in learning and that development needs to take into account identity, power, and systems.

Recommendations. This community-based inquiry project has practical implications for the future of cross-cultural leadership coaching. Based on our experience, we offer a set of recommended practices to assist in surfacing issues associated with identity, power, and systems in the pursuit of maintaining a reciprocal leadership coaching partnership across culture and context. 
1. Establish ethical dimensions of cross-cultural leadership learning and development practice framework and respond to the framework in writing. The IRB application was our chosen framework, but any written document that acknowledges and establishes ethical practice would be advised. Future practice scholarship might consider establishing ethical frameworks more directly appropriate for community-based leadership learning and development practice.

2. Keep detailed records of planning, execution, reflection, and assessment of leadership learning and development practice. We created and maintained written work, reflective writing, photos, audio recordings, and associated transcripts of the leadership coaching sessions as part of our practice. These materials helped us point to specific moments when culture and context become relevant to our leadership coaching partnership. We were more effective at maintaining a reciprocal leadership coaching partnership by attending to issues when they became visible in the records. Over time, we both become better at attending to culture and context issues within the leadership coaching process as a result of maintaining detailed records of our practice.

3. The IDI framework provided a lens to talk about circumstance in which our leadership coaching conversation was bumping up against different ways to see and experience the world. This common way to talk about and make sense of culture and context could represent how the leadership coaching process can be a meaningful intervention in advancing community development efforts.

Conclusion. This practice reminded us that identity is what locks us into existing systems of power. Without a general recognition of the interlocking nature of identity, power, and systems, the coaching partnership maintains existing relations and dynamics of the status quo. Leadership coaching practices that attend to identity, power, and systems can create individual and collective fractures that are required for change.

This paper highlights how accounting for issues of identity, power, and systems enables reciprocal cross-cultural leadership coaching partnerships. Thus, leadership educators who seek to engage in cross-cultural leadership coaching practice ought to take account of identity, power, and systems when attempting to negotiate reciprocal leadership coaching partnerships. Our community-based inquiry surfaced clearly that leadership coaching does not operate in a cultural vacuum. The leadership coaching relationship was strengthened by openly and intentionally considering how power, identity, and systems impact our capacity to maintain a reciprocal leadership coaching relationship. Our leadership coaching partnership has continued well beyond the life of the specific Reciprocal Exchange project highlighted in this manuscript. In fact, up the point of submitting this practice paper, we still maintain a leadership coaching partnership. Our ability to connect via videoconference has become more difficult as a result of connectivity issues, but we still regularly exchange leadership coaching conversations over email. The longevity of our partnership can be partially attributed to the intentional effort we made to maintain a reciprocal leadership coaching relationship.

The Mandela Washington Fellowship for Young African Leaders is made possible by the generous support of the American people through the U.S. Department of State and administered by IREX. This publication was produced independently by Brandon W. Kliewer and Beth Wanjiku Ndirangu and in no way represents official views of the U.S. Government, IREX, or other official entity administering the Fellowship. 


\section{References}

Abbot, G. N., \& Salomaa, R. (2107). Cross-cultural coaching: An emerging practice. In T.Bachkirova, G. Spense, and D. Drake (Eds.), Cross-cultural coaching: An emerging practice (pp. 453-469). Thousand Oaks, CA: Sage.

Allen, A. (2016). The end of progress: Decolonizing the normative foundations of critical theory. New York, NY: Columbia University Press.

Bennett, M. J. (1993). Towards ethonorelativism: A developmental model of intercultural sensitivity. In R. M. Paige (Ed.), Education intercultural experience (pp. 21-71). $\quad$ Yarmouth, ME: Intercultural Press.

Cunliffe, A. L. (2009). The philosopher leader: On relationalism, ethics, and reflexivity-A critical perspective to teaching leadership. Management Learning, 40(1), 87-101.

Dositilio, L. D., Brackmann, S. M., Edwards, K. E., Harrison, B., Kliewer, B. W., \& Clayton, P. H. (2012). Reciprocity: Saying what we mean and meaning what we say. Michigan Journal of Community Service Learning, 19(1), 17-32.

Fairhurst, G. T. (2007). Discursive leadership: In conversation with leadership psychology. Los Angeles, CA: SAGE.

Fairhurst, G. T., \& Antonakis, J. (2012). Dialogue: A research agenda for relational leadership. In M. Uhl-Bien and S. M. Ospina (Eds.), Advancing relational leadership research: A dialogue among perspectives (433462). Charlotte: Information Age Publishing.

Guramtunhu, Cooper, N. M., \& Lyons, L. M. (2017). Moving from competing to complementary: Understanding the influence of personal narratives when designing leadership studies Curriculum. Journal of Leadership Education, 16(4), 94-110.

Hammer, M. R. (2011). Additional cross-cultural validity testing of the Intercultural Development Inventory. International Journal of Intercultural Relations, 35, 474-482.

Heron, J., \& Reason, P. (2001). The practice of co-operative inquiry: Research "with" rather than "on" people. In P. Readon \& H. Bradbury (Eds.), The Handbook of action research: Participative inquiry and practice (pp. 179-188). Thousand Oaks, CA: Sage Publications.

Holland, J. H. (2006). Studying complex adaptive systems. Journal of Systems Science \& Complexity, 19(1), $1-8$.

Kolb, D. (1984). Experiential learning: Experience as the source of learning and development. Upper Saddle River, NJ: Person Education.

Ospina, S. M., \& Foldy, G. (2016). Collective dimensions of leadership. In A. Farazmand (Ed.), Global Encyclopedia of public administration, public policy, and governance (pp. 1-6). New York, NY: Springer.

Passmore, J., \& Law, H. (2013). Cross cultural and diversity coaching. In J. Passmore (Ed.), Cross cultural and diversity in coaching: Working with gender, culture, race, and age (pp. 4-6). London, UK: Kogan Page. 


\section{References}

Raelin, J. (2007). Toward an epistemology of practice. Academy of Management Learning \& Education, 6(4), 495-519.

Rosinski, P. (2003). Coaching across cultures. London: Nichols Brealey Publishing.

Senge, P. (2006). The fifth discipline: The art and practice of the learning organization. NewYork, NY: Doubleday.

Stoecker, R. R. (2012). Research methods for community change: A project-based approach (2nd ed.). Thousand Oaks, CA: Sage.

Stroh, D. P. (2015). Systems thinking for social change: A practical guide to solving complex problems, and achieving lasting results. White River Junction, VT: Chelsea Green Publishing.

Uhl-Bien, M. (2006). Relational leadership theory: Exploring the social process of leadership and organizing, The Leadership Quarterly, 17(6), 654-676.

Wolgramm, R., Spiller, C., \& Voyageur, C. (2016). Special issue: Indigenous leadership -Editors' introduction. Leadership, 12(3), 263- 269. 